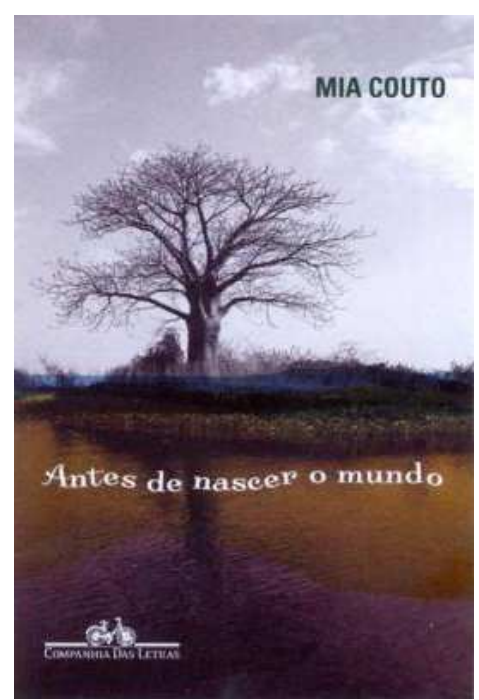

\title{
Antes de nascer o mundo, de Mia Couto
}

\author{
Sueli Saraiva*
}

Velhos subúrbios, tudo em mim é alegoria

(Baudelaire, "O cisne" in.: Flores do Mal)

Estas estórias desadormeceram em mim sempre a partir de qualquer coisa acontecida de verdade mas que me foi

contada como se tivesse ocorrido na outra margem do mundo. Na travessia dessa fronteira de sombra escutei vozes que vazaram o sol. Outras foram asas no meu voo de escrever.

(Mia Couto in.: Vozes anoitecidas)

Daqui a três anos, em 2012, a literatura de língua portuguesa estará comemorando os vinte anos de publicação de Terra Sonâmbula, romance de estreia do moçambicano Mia Couto e considerado um dos dez melhores livros africanos do século XX. Não é exagero começar a ensaiar, ou melhor, a refletir sobre o significado da festa. Se há um escritor contemporâneo cujo projeto literário-romanesco tem seguido um caminho seguro através do exercício de um discurso coerente, esse autor é Mia Couto. Hoje se somam ao romance de 1992 mais sete

\footnotetext{
* Doutoranda em Estudos Comparados de Literaturas de Língua Portuguesa. USPCAPES. Pesquisa: A representação das elites em romances africanos contemporâneos. Contato: suelisaraiva@usp.br
} 
narrativas longas, que já resultaram em dezenas de teses e dissertações acadêmicas, além de despertar um número expressivo de leitores para a riqueza das variações estilísticas da narrativa de língua portuguesa.

No cerne de tal projeto literário está, sem dúvida, a preocupação do escritor de criar situações narrativas capazes de representar a história recente de seu país: mais precisamente, desde a emancipação politica, em 1975, seguida de arrastados dezesseis anos de conflitos civis, findos em 1992, e por fim "the day after", isto é, Moçambique hoje. Nos meandros de sua ficção, ganha vida portanto a história de um povo que prossegue no tratamento de feridas e no reencontro com os novos tempos. Nesse contexto, são emblemáticos, além da primazia de Terra Sonâmbula, também A varanda do frangipani (1996), O último voo do flamingo (2000) e Um rio chamado tempo, uma casa chamada terra (2002). A esse honorável time juntou-se recentemente Antes de nascer o mundo (ANM) - título no Brasil para a versão original, Jesusalém, conforme mantido na edição portuguesa.

Jesusalém é um topônimo inventado num ato, que se poderia chamar de insana lucidez, de um homem diante da corrupção da Humanidade. No enredo, o recém-viúvo Silvestre Vitalício, movido pelas circunstâncias brutais que cercaram a morte de sua bela e infeliz esposa, Dordalma, toma para si a missão de fazer desaparecer da face da terra o homem, os animais, o mundo enfim, colocando em prática o mito bíblico. Mas, sem os poderes supremos para invocar água ou fogo para a total destruição, ele simplesmente pressupõe que o mundo não mais existe, que chegou subitamente o fim dos tempos, abrindo-se as páginas do último livro das Escrituras:

- O caso foi o seguinte: o mundo acabou mesmo antes do fim do mundo...

Terminara o universo sem espectáculo, sem rasgão nem clarão. Por definhamento, exaurido em desespero. (ANM, p. 22)

Silvestre Vitalício, no entanto, inverte a mitologia bíblica, em que o apocalipse é o último destino da humanidade. Ao contrário, ao 
declarar o fim do mundo, ele abandona a cidade com seus dois filhos, um militar e uma jumenta, iniciando uma longa jornada em busca de seu Monte Ararate, o destino da Arca de Noé:

- À frente, enfiado no banco dianteiro, seguia meu pai. Parecia enjoado, talvez ele tivesse assumido que viajava mais num barco que numa viatura. - Isto aqui é a Arca de Noé motorizada Proclamou quando ainda tomávamos lugar na velha carripana. (ANM, p. 19)

Ainda diferentemente da história bíblica, na "Arca" de Silvestre Vitalício a única fêmea permitida era a jumenta Jezibela (talvez uma corruptela de Jezabel, a maldita rainha bíblica). As mulheres estariam banidas da nova humanidade!

A despeito das paródias bíblicas, a começar pelo título brasileiro, aludindo ao Gênesis, sendo Jesusalém "a terra onde Jesus haveria de se descrucificar" (ANM, p.11) e um lugar em que "um dia, Deus nos virá pedir desculpa” (ANM, p. 20), a narrativa insere-se no conjunto da obra de Mia Couto traçando um retrato "nu e cru", como seus narradores costumam dizer, do atordoamento que assola o indivíduo frente aos desafios do presente.

Pode-se inferir que sejam os anos oitenta e noventa, em Moçambique, pois embora o livro não forneça datas e lugares, ele menciona a trágica morte do presidente num acidente, quiçá em alusão às circunstâncias da morte de Samora Machel em 1986: "- Mataramlhe! Sacanas, mataram-lhe!" (ANM, p. 76). Eram, portanto, tempos de guerra civil: "Em redor, a guerra tornara tudo vazio, sem sombra de humanidade..." (ANM, p. 20) e a nova morada da humanidade, criada por Silvestre Vitalício, nada mais era do que uma região de caça, uma coutada abandonada. Como se sabe, as agruras da guerra civil atingiam de forma mais violenta as zonas rurais, levando as populações a migrarem forçosamente para as áreas urbanas.

O enredo de Antes de nascer o mundo é apresentado segundo as reminiscências de um narrador em primeira pessoa: Mwanito, filho de 
Silvestre Vitalício e órfão de Dordalma, rememora os anos de sua infância em que acreditava que a humanidade se resumia a cinco humanos e uma jumenta (um animal com status de gente); e que todo o mundo era aquele lugar para onde foi levado aos três anos de idade pelo pai: “- Este é o país derradeiro e vai-se chamar Jesusalém” (ANM, p. 37).

A narrativa é dividida em três livros. No primeiro, intitulado "A humanidade", o narrador dedica um capítulo a cada personagem desse grupo de remanescentes: ele próprio, Mwanito; seu pai, Silvestre Vitalício; seu irmão, Ntunzi; Zacaria Kalash, o militar; a jumenta Jezibela e o Tio Aproximado. A última personagem não reside em Jesusalém, mas vem ocasionalmente do "Lado-de-Lá", conforme dizia o chefe do clã, recusando-se a confirmar a existência, de fato, de qualquer outro lugar.

O "Livro dois" é intitulado "A visita". Neste ponto já havia transcorrido oito anos desde a chegada do grupo à nova terra. Mwanito já contava onze anos de idade, conforme relata na abertura do livro: "A primeira vez que vi uma mulher tinha onze anos e me surpreendi subitamente tão desarmado que desabei em lágrimas” (ANM, p. 11). Neste ponto, o castelo de sonhos de Silvestre Vitalício começa a ruir quando uma importante regra é quebrada com a chegada de uma mulher, a portuguesa Marta (um outro nome de referência bíblica).

A "visita" da mulher cria não somente uma viravolta no enredo, mas introduz no romance uma das características distintivas de Mia Couto, isto é, a presença de uma segunda voz narrativa, dialogando com o narrador principal por meio de cartas. Marta narra desse modo a sua própria história, os motivos de sua partida de Lisboa até a chegada em Jesusalém. Tais escritos são denominados, de forma ambivalente, de "Os papéis da mulher" e "Segundos papéis". Na figura de Marta, a mulher que veio renascer em e trazer vida a Jesusalém, a narrativa vai recuperar as vozes femininas apartadas daquele mundo imperado pelo masculino: "Sou mulher, sou Marta e só posso escrever" (ANM, p. 131). 
O "Livro três" é o momento das "Revelações e Regressos", conforme assinala o título. Aqui tem início o desfecho da narrativa. A vinda da mulher, a rebeldia do filho mais velho e a tomada de consciência de Mwanito sobre a existência de um "outro mundo" convergem para o desmoronamento final da fantasia de Silvestre Vitalício e seu desejo de proteger, por amor, os filhos da perversidade do mundo.

Essa última parte traz um subtítulo instigante: "O livro". Aqui a metalinguagem, outro traço característico de Mia Couto, apresenta-se com toda a força de sua prosa poética. O narrador, então com dezesseis anos, confessa ao irmão as consequências de sua experiência passada em Jesusalém, as quais resultaram na escrita do "livro":

— Veja estes papeis — disse, estendendo um maço de páginas caligrafadas.

Tudo aquilo eu redigira nos momentos de escurecimento. Atacado por cegueira deixava de ver o mundo. Só via letras, tudo o resto eram sombras. (ANM, p. 275)

Aqui são retomados os temas da cegueira necessária para "enxergar" um mundo em desagregação e da escrita enquanto locus de revelação daquilo que está na sombra, que se encontra além da razão; enfim, ele recorda o papel da arte como tradutora dos mais profundos sentimentos de humanidade. Nessa narrativa poeticamente quixotesca - mas de um Cavaleiro da Triste Figura que fracassa em seu quixotismo por tentar escapar ao mundo -, Mia Couto ensina pela voz de Mwanito: “Quem perde esperança foge. Quem perde confiança esconde-se. E ele queria as duas coisas: fugir e esconder-se. Mas nunca suspeitássemos de haver em Silvestre um sentimento de desamor" (ANM, p. 75). Quem tiver esperança e confiança para enfrentar os moinhos de vento que o faça aqui e agora.

COUTO, Mia. Antes de nascer o mundo. São Paulo: Companhia das Letras, 2009, 280 p. 